\title{
A INTERPRETAÇÃO DA PROVA ILÍCITA COMO GARANTIA PROCESSUAL PENAL NA SUPREMA CORTE DOS ESTADOS UNIDOS, DE WEEKS (1914) A HERING (2013): BREVES APONTAMENTOS SOBRE A CONVERGÊNCIA AXIOLÓGICA, OU NÃO, COM A PROVA ILÍCITA NO BRASIL
}

\author{
INTERPRETATIVE TRAJECTORIES OF PROCEDURAL GUARANTEES: THE \\ DECONSTITUTIONALIZATION OF THE DOCTRINE OF EXCLUSION OF ILLEGAL \\ EVIDENCE IN THE SUPREME COURT OF THE UNITED STATES AND THE BRAZILIAN \\ PROPOSAL TO RELATIVIZE ILLICIT EVIDENCE
}

Evandro Piza Duarte

Graduação em Direito pela Universidade Federal de Santa Catarina, Mestrado em Direito pela UFSC e Doutorado em Direito pela Universidade Nacional de Brasília (UnB). Professor na Universidade de Brasília UnB de Direito Penal, Processo Penal e Criminologia.

E-mail: evandropiza@gmail.com

Thales Cassiano Silva

Bacharel em Direito da Faculdade de Direito da Universidade de Brasília - FD/UNB. E-mail: thalescassiano@gmail.com

Recebido em: 10/09/2018

Aprovado em: 04/08/2020

RESUMO: O texto tem por objetivo destacar o status quo do atual do debate constitucional sobre doutrina da exclusão da prova ilícita dos Estados Unidos (EUA). A análise da construção da doutrina de exclusão de provas ilícitas no sistema jurídico constitucional norte-americano é feita a partir dos argumentos apresentados em precedentes da Suprema Corte. O período considerado compreende desde a criação da exclusionary rule (Weeks v. United States - 1914), passando pelo seu reconhecimento como regra constitucional obrigatória aos estados (Wolf v. Colorado e Mapp v. Ohio), até a decisão que provoca sua desconstitucionalização (Calandra v. United States - 1974) e, por fim, os precedentes que situam de forma preocupante o atual contexto de aplicação da regra (Hudson v. United States - 2006 - e Herring v. United States - 2009). O estudo da criação da regra e sua interpretação atual visam a possibilitar uma intepretação contextualizada da utilização da prova ilícita e boa-fé naquele ordenamento. Ao final, texto tece considerações sobre a impossibilidade da incorporação acrítica da trajetória jurisprudencial americana por parte da doutrina brasileira, a qual pretende a relativização da prova ilícita com uma interpretação problemática que viola os padrões argumentativos norte-americanos e, especialmente, as garantias formais do sistema jurídico constitucional brasileiro.

Palavras-chave: Processo Penal. Provas ilícitas. Exclusionary Rule. Suprema Corte dos Estados Unidos. 
ABSTRACT: The purpose of the text is to distinguish between the place occupied by the doctrine ofexclusion of illicit evidence in the United States and in the Brazilian constitutional system. It analyzes the construction of the doctrine of exclusion of illegal evidence in the American constitutional legal system based on arguments of the Supreme Court of the United States. The period in question comprises the creation of the exclusion rule (Weeks v. United States - 1914), its recognition as a constitutional rule binding upon the states (Wolf v. Colorado and Mapp v. Ohio), the decision leading to its deconstitutionalization (Calandra v. United States - 1974) and lastly, the precedents that worryingly place the present context of the application of the rule (Hudson $\mathrm{v}$. United States - 2006 - and Herring v. United States - 2009). The text highlights the reason why the interpretative trajectory of American deconstitutionalization does not authorize an uncritical appropriation of this peculiar constitutional logic by the Brazilian doctrine, which aims to relativize the illicit proof. Instead, it suggests how the import of arguments constitutes, in fact, a problematic creation that violates American argumentative standards, especially the formal guarantees of the Brazilian constitutional legal system.

Keywords: Penal Procedure. Illegal Evidence. Exclusionary Rule. Supreme Court of the United States.

SUMÁRIO: Introdução; Método de análise e justificação dos precedentes escolhidos; 1. O reconhecimento de um Direito Constitucional: A formulação da doutrina da Exclusionary Rule, Weeks v. United States (1914); 2. A aposta em estratégias diversas da exclusão da prova para a garantia da eficácia da IV Emenda: Wolf v. Colorado (1949); 3. O ápice da curva ascendente das garantias processuais: Mapp v. Ohio (1961); 4. A redução da doutrina da exclusão a uma teoria da inibição, o início do processo de desconstitucionalização: Calandra v. United States (1974); 5. A ameaça direta à doutrina da exclusão: Hudson v. Michigan (2006); 6. A desconstitucionalização da regra da exclusão e o ataque aos direitos explícitos na IV Emenda: Herring v. United States (2009); 7. Trajetórias interpretativas e a ameaça de desconstitucionalização autoritária; Bibliografia

\section{INTRODUÇÃO}

Os sistemas penais ocidentais racionalizaram a verdade processual em torno da ideia da prova, ou seja, a formação de culpa passou a prescindir de evidências. ${ }^{12}$ Porém, nem todas as formas de prova são admitidas em direito. O que fazer com as provas produzidas em desrespeito aos direitos fundamentais? Deve-se considerá-las ilícitas? ${ }^{3}{ }^{4}$ As definições das situações de ilicitude e as consequências dessa ilicitude são objeto de intensa discussão, até porque a valoração da prova ocorre no caso concreto e a realidade social é sempre mutante. A jurisprudência nem sempre cria critérios suficientes para esta valoração, este contexto torna a matéria de relevância nos debates constitucionais em diversos países nos quais as constituições propugnam pela garantia das liberdades individuais.

No caso norte-americano, a compreensão de como as garantias constitucionais são aplicadas materialmente em procedimentos processuais penais depende da análise dos princípios e regras constitucionais construídos nos precedentes a respeito da IV Emenda da Constituição,

\footnotetext{
${ }^{1}$ Kant de Lima, Roberto. Direitos civis e Direitos Humanos: uma tradição jurídica pré-republicana? São Paulo em perspectiva, São Paulo, v. 8, p.49-59, jan./mar. 2004, p. 49-59.

${ }^{2}$ Ferrajoli, Luigi. Direito e razão: teoria do garantismo penal. São Paulo: RT, 2002.

${ }^{3}$ Estrampres, Manuel Miranda. La prueba ilícita: la regla de exclusion probatoria y sus excpeciones. Revista Catalana de Seguretat, p. 131-151, 2010, p.54.

${ }^{4}$ COOLEY, Thomas M. Princípios Gerais de Direito Constitucional nos Estados Unidos da América. Belo Horizonte: Universal, 2016.
} 
responsável por regular os direitos dos cidadãos diante das buscas e apreensões por parte de autoridades estatais de elementos que possam se configurar como prova em processo judicial. ${ }^{5}$

A IV Emenda é um dispositivo constitucional essencial à doutrina do devido processo legal $^{6}$, uma vez que institui procedimentos processuais que regulam à inviolabilidade do lar e a proteção da intimidade, que são oponíveis ao Estado Polícia e ao Estado Juiz. Ocorre que esta Emenda é uma das que remontam ao Bill of Rights ${ }^{7}$ - o qual consiste no conjunto das dez primeiras emendas da Constituição dos Estados Unidos -, elaboradas com intuito de garantir direitos dos cidadãos oponíveis à União. Consequentemente, tal conjunto não vinculava diretamente os Estados Federados, ou seja, eram garantias de âmbito federal. Como se verá a seguir, a exclusão de provas que violassem o conteúdo material dessa emenda foi reconhecida pela Suprema Corte como direito constitucional muito antes de vincular o Sistema Judiciário dos estados, e, especialmente, antes de ser considerada como procedimento autônomo aplicável a outros dispositivos constitucionais, além da IV Emenda.

As definições das situações de ilicitude previstas na IV Emenda e as consequências do reconhecimento dessas hipóteses foram objeto de longo debate. Em Weeks v. United States ${ }^{8}$ a Suprema Corte criou a regra da exclusão de provas ilícitas (exclusionary rule), por considerá-la uma decorrência lógica da IV Emenda, uma vez que possibilitaria seus efeitos materiais. ${ }^{9}$ As provas adquiridas em desconformidade aos ditames estipulados nessa Emenda passaram a ser rechaçadas. ${ }^{10}$

Na ocasião, a Suprema Corte sinalizou o entendimento de que para a materialização das garantias procedimentais era necessário que ela fosse aplicada como um remédio constitucional essencial à emenda. Como consequência, o desrespeito aos seus procedimentos passou a ser considerado como violação material ao devido processo legal que é um direito fundamental do cidadão amplamente reconhecido pela XIV Emenda.

No entanto, os Estados não submeteram seus procedimentos judiciais à aplicação da regra da exclusão, pois, conforme Wolf $v$. Colorado ${ }^{11}$, eles detinham competência para decidir sobre a aplicação da garantia nos crimes estaduais. A vinculação da jurisdição estadual só viria a ocorrer em Mapp v. Ohio $^{12}$, quando pela primeira vez a Suprema Corte declarou, simultaneamente, a imposição pela Constituição da necessidade da regra da exclusão por meio da IV Emenda e a inclusão dessa garantia como decorrente do devido processo legal. Portanto, decidiu estender os efeitos da regra da exclusão como consequência lógica da XIV Emenda, esta sim de imposição obrigatória para os casos de jurisdição estadual e federal.

Nesse contexto é que se pode falar de uma constitucionalização da regra da exclusão da prova ilícita, o que na prática significou a declaração pela Suprema Corte de que excluir a prova ilícita era uma consequência lógica do reconhecimento da ilicitude da prova e, portanto, integrada ao sistema constitucional, e, em seguida, o reconhecimento de que se estava diante de uma garantia imposta pela XIV Emenda, inerente ao devido processo legal.

\footnotetext{
${ }^{5}$ IV Emenda: O direito das pessoas de estarem seguras em suas pessoas, casas, documentos e propriedades em face de buscas e apreensões desarrazoadas não deve ser violado, e nenhum mandado deve o infringir, exceto quando calcado em causa provável, fundamentado por juramento, e descritos particularmente o local a ser investigado e as pessoas ou coisas a serem apreendidas (Tradução nossa).

${ }^{6}$ Re, Richard M. The due process exclusionary rule. Harvard Law Review, v. 127, n. 7, p. 1887-1966, 2014, p. 19071910.

${ }^{7}$ Segundo Burt Neuborne, em Fundamentals of American Law (1996), o bill of rights é a declaração de direitos dos Estados Unidos da América, documento ratificado em 15 de dezembro de 1791, composto pelas 10 primeiras emendas à Constituição dos Estados Unidos.

${ }^{8}$ Estados Unidos. Suprema Corte. Weeks v. United States, 1914, p. 396-399.

${ }^{9}$ Re, Richard M. The due process exclusionary rule. Harvard Law Review, v. 127, n. 7, p. 1887-1966, 2014, p. 19071910, p. 1934.

${ }^{10}$ Estados Unidos. Suprema Corte. Weeks v. United States, 1914, p. 398.

${ }^{11}$ Estados Unidos. Suprema Corte. Wolf v. Colorado, 1949, p. 33.

${ }^{12}$ Estados Unidos. Suprema Corte. Mapp v. Ohio, 1961, p. 685.
}

Revista de Direito Brasileira | Florianópolis, SC | v. 27 | n. 10 | p.216-240 | Set./Dez. 2020 
Todavia, como se verá, o processo de constitucionalização foi seguido de decisões que intentaram minimizar e inverter a posição inicial da Suprema Corte. Tais tensões geraram um profundo debate na doutrina americana que pode ser sintetizado, inclusive, nos títulos de alguns artigos produzidos sobre essa polêmica que utilizam as expressões "morte" ou "ataque" à regra da exclusão. 131415

O presente artigo apresenta quais foram os fundamentos dessas mudanças, demonstrando como o debate estadunidense tem como pano de fundo a disputa sobre o caráter constitucional da regra da exclusão. Portanto, a possibilidade de se advogar a constitucionalização ou não constitucionalização repousa numa controvérsia sobre o pertencimento à Constituição da doutrina da exclusão.

\section{Método de análise e justificação dos precedentes escolhidos.}

Na organização e na escolha das decisões que compõem o objeto da pesquisa, utilizou-se Metodologia de Análise de Decisões (MAD), ferramenta destinada à realização de pesquisas jurídicas com especial enfoque no estabelecimento de procedimentos de análise de decisões judiciais e jurisprudência ${ }^{16}$.

O problema de pesquisa foi definido a partir do interesse em entender o "estado da arte" do debate constitucional sobre a prova penal ilícita na Suprema Corte dos Estados Unidos, isso porque parte da bibliografia processual penal brasileira se utiliza das decisões daquele tribunal como fonte de direito comparado. O objetivo específico da pesquisa foi investigar o contexto da adoção da exceção da prova ilícita de boa-fé, a qual se pretendeu "importar" ao ordenamento brasileiro no projeto de lei das 10 medidas contra corrupção, formulado por grupos da sociedade civil, encabeçados pela força tarefa da Lava Jato em Curitiba. A partir dessa pretensão, identificou-se os stares decisis sobre o tema na Suprema Corte dos Estados Unidos - recorte institucional ${ }^{17}$.

Para a compreensão e estudo do objeto definido, analisou-se a decisão que criou a regra de exclusão de provas ilícitas, doutrina sobre a qual recai a apontada exceção (Weeks v. United States); investigou-se os dois precedentes que levantaram a hipótese de vinculação, ou não, das cortes estaduais à regra de exclusão de provas (Wolf v. Colorado e Mapp v. Ohio); estudou-se a decisão que superou parcialmente (overrruling) o precedente inicial (Calandra v. United States) e, por fim, observou-se as duas decisões atuais que fecham o ciclo de decisões que pretenderam superar ou reduzir a amplitude da doutrina criada em Weeks (Hudson v. United States e Herring v. United States) - recorte objetivo definido por hipótese ${ }^{18}$. A detalhamento da justificação das escolhas dessas decisões e sua respectiva relevância temática estão nos tópicos específicos que analisa cada uma delas.

\footnotetext{
${ }^{13}$ Bradley, Craig. Is the exclusionary rule dead? The Journal of Criminal Law and Criminology, Vol. 102, No. 1, pp. 1-23. Chicago: Northwestern University School of Law, Winter 2010.

${ }^{14}$ Bradley, Craig M. Red Herring or the death of the exclusionary rule? Trial Magazine, Indiana Legal Studies Research Paper, No. 129. Washigton: The American Association for Justice, 2009.

${ }^{15}$ LaFave, Wayne R. The Smell of Herring: A Critique of the Supreme Court's Latest Assault on the Exclusionary Rule, 99 J. Crim. L. \& Criminology 757, 77778 (2009).

${ }^{16}$ FILHO, ROBERTO FREITAS; LIMA, T. M. Metodologia de Análise de Decisões - MAD. Universitas Jus, v. 21, p. $1-18,2010$.

${ }^{17} \mathrm{O}$ recorte institucional diz respeito à escolha dos órgãos decisores que vão ser pesquisados. A decisão sobre esse aspecto do recorte metodológico deve levar em conta a pertinência funcional do decisor ou do grupo de decisores. Assim, é possível investigar: (...) a) Quanto à pluralidade interna de decisores (..) a.2) um único órgão colegiado.

18 Por hipótese, o pesquisador pode identificar como problema relevante a ser investigado a oposição entre dois princípios (são exemplos a oposição entre o "sigilo de correspondência" e a "segurança da coletividade" ou entre a "vedação do enriquecimento sem causa" e a "aplicação da função punitiva da indenização por dano extra patrimonial").

Revista de Direito Brasileira | Florianópolis, SC | v. 27 | n. 10 | p.216-240 | Set./Dez. 2020
} 
De modo geral, as decisões ${ }^{19}$ escolhidas para apresentar esse debate respondem às seguintes perguntas: as provas apresentadas foram obtidas nos conformes constitucionais? E se não foram, quais são as consequências para o seu uso no processo penal como forma de racionalização da certeza judicial? Em sua maioria, referem-se a casos em que buscas e apreensões foram realizadas por autoridades policiais de maneira duvidosa desde a perspectiva da análise da licitude das provas. O interesse em apresentá-las e o modo como elas se constituíram em precedentes em seu sistema constitucional de origem decorre, em primeiro lugar, de uma evidência quase cotidiana, a centralidade das garantias formais no debate público, e em segundo lugar, em razão da crescente referência à doutrina americana nos julgados brasileiros. ${ }^{20}$

Ao final, após definição do contexto jurisprudencial em que se dá exceção da boa-fé, são feitos breves apontamentos sobre a comparação proposta entre os dois ordenamentos, especialmente pelo projeto de lei das 10 medidas contra corrupção e da teoria do garantismo penal integral, destacando-se o tentativa de criação da prova ilícita boa-fé no ordenamento jurídico nacional.

\section{O RECONHECIMENTO DE UM DIREITO CONSTITUCIONAL: A FORMULAÇÃO DA DOUTRINA DA EXCLUSIONARY RULE, WEEKS V. UNITED STATES (1914)}

Em Weeks v. United States foi reconhecida a necessidade de criar um remédio constitucional para materializar as garantias constitucionais da IV Emenda ${ }^{21}{ }^{22}$. No referido caso, o Senhor Fremont Weeks teve a casa invadida pela polícia, sem mandado judicial, e lá foram apreendidas evidências que o ligavam a práticas criminosas. ${ }^{23}$ Tais provas ensejaram sua condenação nos dois graus de jurisdição do Estado do Missouri. ${ }^{24}$ Seria possível manter uma condenação com base em provas adquiridas dessa forma? Se não fosse, quais seriam as consequências? Caso as provas pudessem ser consideradas ilegais pela Suprema Corte, quais seriam as consequências concretas para o investigado, investigador e para o processo como um todo?

A preocupação era pragmática e o debate colocava em evidência as práticas cotidianas do processo penal. Apesar da resposta da exclusão parecer lógica para o caso, essa não era uma teoria presente no ordenamento jurídico americano à época. Porém, a Suprema Corte decidiu que:

\footnotetext{
19 Aborda-se a instituição/criação da exclusionary rule (Weeks v. United States - 1914), passando pelo seu reconhecimento como obrigatória aos estados (Wolf v. Colorado e Mapp v. Ohio), até a decisão de desconstitucionalização da regra (Calandra v. United States - 1974) e, por fim, os precedentes que tendem, na prática, negar a aplicação da regra da exclusão (Hudson v. United States - 2006 - e Herring v. United States - 2009).

${ }^{20}$ Tais aspectos têm sido tematizados por: Wanderley, Gisela Aguiar. Liberdade e Suspeição no Estado de Direito: o poder policial de abordar e revistar e o controle judicial de validade da busca pessoal. Dissertação de mestrado no curso de Pós-Graduação em Direito da Universidade de Brasília, 2017; Garcia, Rafael de Deus. O Uso da Tecnologia e a Atualização do Modelo Inquisitorial: Gestão da Prova e Violação de Direitos Fundamentais na Investigação Policial na Política de Drogas. Belo Horizonte: Lumen Juris, 2017.

${ }^{21}$ Re, Richard M. The due process exclusionary rule. Harvard Law Review, v. 127, n. 7, p. 1887-1966, 2014, p. 19071910, p. 1934.

${ }^{22}$ Estados Unidos. Suprema Corte. Weeks v. United States, 1914, p. 398.

${ }^{23}$ Nos Estados Unidos, em 1911, o Senhor Fremont Weeks foi preso por supostamente transportar bilhetes de loterias por correspondência, valendo-se das facilidades que o emprego em uma empresa de encomendas lhe proporcionava. Logo após prisão, policiais do distrito de Kansas City foram a sua residência - sem mandado judicial -, conseguiram a chave da casa, por meio de uma informação dada por um vizinho, e nela ingressaram. Durante esta busca, apreenderam documentos e os entregaram a policiais federais. Algumas horas depois, ainda sem mandado judicial, os policiais federais voltaram a casa do senhor Fremont Weeks junto aos policiais do distrito, e lá realizaram uma nova apreensão, sendo que desta vez foram apreendidos envelopes e cartas que estavam em móveis da casa. (Estados Unidos. Suprema Corte. Weeks v. United States, 1914, p. 386).

${ }^{24}$ Estados Unidos. Suprema Corte. Weeks v. United States, 1914, p. 384.
}

Revista de Direito Brasileira | Florianópolis, SC | v. 27 | n. 10 | p.216-240 | Set./Dez. 2020 
Se cartas e documentos pessoais podem ser apreendidos, custodiados e usados como evidência contra um cidadão acusado de um crime, a proteção da IV emenda, que declara o direito do cidadão de estar seguro contra tais buscas e apreensões, não tem valor algum, e, para aqueles que se encontram nessa situação, ela pode muito bem ser retirada da Constituição. Os esforços das Cortes e de oficiais em punir o culpado, louváveis como são, não podem se valer do sacrifício daqueles grandes princípios estabelecidos durante anos de esforço e sofrimento que resultaram em sua personificação na lei máxima do Estado. (Tradução nossa) ${ }^{25}$

Ademais, concluiu que o instrumento utilizado para dar a eficácia desejada deveria ter status constitucional. A regra da exclusão de provas ilícitas surgia como um remédio constitucional, sendo concebida como uma derivação lógica da IV Emenda. No voto condutor do Justice Day, seguido unanimemente pelos seus pares, ela foi reconhecida como elemento interpretativo indispensável à referida emenda e, dessa forma, convertia-se, por óbvio, em direito fundamental do cidadão:

O efeito da IV emenda é submeter as cortes dos Estados Unidos e os agentes federais, no exercício de seu poder e autoridade, à limitações e restrições no exercício destes, e para sempre garantir a segurança de todas as pessoas, casas, documentos e haveres contra qualquer tipo de buscas desarrazoadas nos moldes da lei. Esta proteção atinge a todos, enquanto acusado de crime ou não, e é seu papel dar-lhe força e obrigatoriedade para todos os jurisdicionados sob o nosso sistema Federal na aplicação das leis. $O$ intuito daqueles que executam a legislação criminal do país para obter condenações por meios ilegais não pode encontrar respaldo nos tribunais de justiça, os quais cumprem seus deveres sem exceção com o apoio da Constituição, e aos quais cidadãos de qualquer condição têm o direito de recorrer para que se mantenha este direito fundamental. (Tradução nossa) ${ }^{26}$

Logo, o processo penal deveria garantir materialmente o direito do cidadão à liberdade. Para tanto, o poder punitivo do Estado necessitava ser constrangido no plano de seus

\footnotetext{
${ }^{25}$ If letters and private documents can thus be seized and held and used in evidence against a citizen accused of an offense, the protection of the 4th Amendment, declaring his right to be secure against such searches and seizures, is of no value, and, so far as those thus placed are concerned, might as well be stricken from the Constitution. The efforts of the courts and their officials to bring the guilty to punishment, praiseworthy as they are, are not to be aided by the sacrifice of those great principles established by years of endeavor and suffering which have resulted in their embodiment in the fundamental law of the land.(texto original) (Estados Unidos. Suprema Corte. Weeks v. United States, 1914, p. 393).

${ }^{26}$ The effect of the 4th Amendment is to put the courts of the United States and Federal officials, in the exercise of their power and authority, under limitations and restraints as to the exercise of such power and authority, and to forever secure the people, their persons, houses, papers, and effects, against all unreasonable searches and seizures under the guise of law. This protection reaches all alike, whether accused of crime or not, and the duty of giving to it force and effect is obligatory upon all [e]ntrusted under our Federal system with the enforcement of the laws. The tendency of those who execute the criminal laws of the country to obtain conviction by means of unlawful seizures... should find no sanction in the judgments of the courts, which are charged at all times with the support of the Constitution, and to which people of all conditions have a right to appeal for the maintenance of such fundamental rights. (texto original) (Estados Unidos. Suprema Corte. Weeks v. United States, 1914, p. 391-392).
}

Revista de Direito Brasileira | Florianópolis, SC | v. 27 | n. 10 | p.216-240 | Set./Dez. 2020 
procedimentos de investigação, não bastando a mera submissão do processo à jurisdição lato sensu, pois os tribunais não poderiam ser refúgio para ilegalidades dessa natureza. ${ }^{2728}$

Em síntese, o pano de fundo da aplicação da exclusionary rule foi o controle da autoridade do Estado e, portanto, a proteção do cidadão diante da autoridade ilegalmente exercida. A regra teria o condão de limitar o uso arbitrário da força pelos agentes do Estado, porque condutas em desrespeito a direitos constitucionais não resultariam no efeito desejado por quem cometesse o ato ilícito, tendo em vista que seriam excluídas do rol de provas judiciais lícitas.

Entretanto, a Suprema Corte não enfrentou a vinculação das cortes estaduais à nova regra, pois o caso concreto não suscitava a questão. ${ }^{29}$ Logo, ela se tornou obrigatória na persecução penal de competência federal ou em diligências executadas por agentes federais, conforme Boyd v. United States 3031 .

\section{A APOSTA EM ESTRATÉGIAS DIVERSAS DA EXCLUSÃO DA PROVA PARA A GARANTIA DA EFICÁCIA DA IV EMENDA: WOLF V. COLORADO (1949)}

O silêncio sobre esse tema deixou em suspenso um debate importante. De fato, não existia unanimidade a respeito da obrigatoriedade da aplicação do Bill of Rights nas cortes estaduais a respeito de qualquer tema. Tanto é assim que ele foi travado em diversos julgados, tais como: Hurtado v. California (1884), Twining v. New Jersey (1908), Brown v. Mississippi (1936) Palko v. Connecticut (1937), intensificando-se, porém, em Wolf v. Colorado (1945), quando as decisões anteriores $^{32}$ são reiteradas e a Corte nega que a regra criada em Weeks pudesse vincular os Estados.

\footnotetext{
${ }^{27}$ Muito embora a análise proposta não exija a adoção do Garantismo Penal, ao final serão usados especialmente os conceitos de submissão à jurisdição lato sensu e stricto sensu, para que se perceba que a mera existência de procedimentos processuais com a presença de um juiz não equivale ao conjunto de garantias previstas na constituição brasileira. E ainda, que tais garantias se impõem às diligências pré-processuais, e, portanto, do controle judicial da atividade policial cotidiana (Duarte, Evandro Piza; Queiroz, Marcos V. Lustosa; Costa, Pedro H. Argolo. "A Hipótese Colonial, um diálogo com Michel Foucault: a Modernidade e o Atlântico Negro no centro do debate sobre Racismo e Sistema Penal". In: "Universitas Jus", v. 27, p. 01-31, 2016). Segundo Vera Regina Pereira Andrade, a oposição entre abolicionismo e garantismo carece de fundamentação. A antítese do abolicionismo não é o minimalismo, mas o eficientismo penal (ou "Lei e ordem"), que tenta apresentar a crise do sistema como crise conjuntural de eficiência. Para o eficientismo, se o sistema não funciona, ou seja, se não combate a criminalidade com eficiência, é porque não é suficientemente repressivo (Andrade, Vera Regina Pereira de. Minimalismos, abolicionismos e eficienticismo: a crise do sistema penal entre a deslegitimação e a expansão. Revista Sequência, no 52, p. 163-182, jul. 2006).

${ }^{28}$ Ferrajoli, Luigi. Direito e razão: teoria do garantismo penal. São Paulo: RT, 2002

${ }^{29}$ Estados Unidos. Suprema Corte. Weeks v. United States, 1914, p. 395.

${ }^{30}$ Takayanagi, Fabiano Yuji. Críticas às exceções legais às provas ilícitas por derivação no processo penal brasileiro e análise de jurisprudência após a reforma da lei 11.690/08. 2014. Dissertação (Mestrado em Direito Processual) - Faculdade de Direito, Universidade de São Paulo, São Paulo, 2014.

${ }^{31}$ Segundo Fabiano Yuji Takanayagi (2014), em Boyd v. United States, foi fixado que a IV Emenda tem função de instrumento garantidor do povo americano contra ingerências das autoridades do governo à privacidade e aos pertences.

${ }^{32}$ Em 17/04/1944, o médico Julius A. Wolf, especialista em obstetrícia, foi preso por suposta conspiração para prática de abortos. A investigação que desencadeou a prisão foi conduzida pelo detetive Ray Humphreys, o qual obteve informações anônimas de mulheres que teriam ou pretendiam realizar abortos com Dr. Wolf. Ocorre que estas evidências basearam a entrada do detetive no consultório particular do médico, local onde realizou busca e apreensões sem a devida autorização judicial. Desta busca, resultou a apreensão de dois diários profissionais, referentes aos anos de 1943 e 1944, em que constavam os nomes e as datas nas quais o médico teria se encontrado com as pacientes que desejavam realizar abortos clandestinos. Com base nestas evidências, o Dr. Wolf foi preso - sem ordem judicial. Posteriormente, em decorrências desses fatos, ele foi acusado duas vezes por conspirar para a prática de abortos, em dois júris distintos, e, em ambos, foi condenado. A principal linha de investigação consistiu em contatar as mulheres listadas no livro e confirmar o contato delas com o médico com o intuito de abortar ou que já teriam abortado. Isto é, o conteúdo do livro foi a principal prova produzida, somada ao testemunho das mulheres, prova que deriva diretamente da anterior. Fatos que permitiriam de pronto a aplicação da teoria dos frutos da árvore envenenada, uma vez que uma prova foi imprescindível ao descobrimento da outra. Estas ilegalidades forma alegadas em matéria de defesa, e foi Revista de Direito Brasileira | Florianópolis, SC | v. 27 | n. 10 | p.216-240 | Set./Dez. 2020
} 
33 Todavia, a dissidência foi relevante, pois os juízes analisaram com mais profundidade os efeitos e as razões que impediriam a vinculação das cortes estaduais. A seguinte hipótese foi levantada:

Uma condenação de Corte Estadual, por um crime estadual, nega o devido "processo legal" requerido pela IV Emenda exclusivamente porque se utilizou em julgamento uma evidência que foi obtida sob circunstâncias que a tornariam inadmissível na persecução penal federal, devido à violação de uma lei federal, em uma Corte dos Estados Unidos da América, na qual é considerada uma infração à quarta emenda, nos moldes de Weeks v. United States? (Tradução nossa) ${ }^{34}$

A XIV Emenda impõe aos Estados a garantia do devido processo legal. Logo, se a regra da exclusão fosse indispensável para o conceito de devido processo legal (due process of law), a Suprema Corte teria que superar o entendimento de que as dez primeiras emendas da Constituição dos Estados Unidos seriam garantias do cidadão em relação apenas à União. Contudo, para o voto condutor do Juiz Franckfurter a regra não possuía conteúdo inerente à aplicabilidade da IV Emenda:

Em Weeks v. United States supra, esta Corte afirmou que em uma persecução federal a IV Emenda proíbe o uso de evidências obtidas por meio de buscas e apreensões ilegais. Esta sentença foi declarada pela primeira vez em 1914. Ela não foi derivada das disposições explícitas da IV Emenda; ela também não se baseou nos comandos legislativos do Congresso com intuito de cumprir a Constituição. A decisão foi uma questão de política judiciária. Desde então, ela tem sido frequentemente aplicada e nós aderimos a ela de maneira resoluta. Entretanto, a questão imediata é se o direito básico à inviolabilidade, em persecução federal, contra buscas arbitrárias realizadas pela polícia, requer a exclusão de provas evidentemente relevantes obtidas através de uma busca e apreensão irrazoável, visto que em uma persecução federal de um crime federal, elas seriam excluídas. Por ser uma questão de causa inerente, essa é uma suposição sobre a qual indivíduos fiéis à proteção das liberdades individuais podem vir a ter posicionamentos diferentes. (Tradução nossa) ${ }^{35}$

A Suprema Corte reafirmou, portanto, que o conteúdo para a incidência da cláusula do devido processo legal deveria ser produzido pela legislação estadual, em outras palavras, os

requerida a exclusão destas provas nos julgamentos do Dr. Wolf. Entretanto, a tese não prosperou, e, aplicando-se o precedente de Weeks v. United States, este fundamento foi rejeitado na Corte Superior do Colorado. Nota-se, em vista disso, que as alegações da defesa foram rejeitadas não pelo mérito da decisão de Weeks v. United States, e sim, pelo reconhecimento de que tal precedente não se aplicava ao caso concreto, uma vez que é um crime estadual. (Estados Unidos. Suprema Corte. Wolf v. Colorado, 1949, p. 33-34)

${ }^{33}$ Estados Unidos. Suprema Corte. Wolf v. Colorado, 1949, p. 47-48.

${ }^{34}$ Does a conviction by a State court for a State offense deny the "due process of law" required by the Fourteenth Amendment, solely because evidence that was admitted at the trial was obtained under circumstances which would have rendered it inadmissible in a prosecution for violation of a federal law in a court of the United States because there deemed to be an infraction of the Fourth Amendment as applied in Weeks v. United States? (Texto original) Estados Unidos. Suprema Corte. Wolf v. Colorado, 1949, p. 26.

35 In Weeks v. United States, supra, this Court held that, in a federal prosecution the Fourth Amendment barred the use of evidence secured through an illegal search and seizure. This ruling was made for the first time in 1914. It was not derived from the explicit requirements of the Fourth Amendment; it was not based on legislation expressing Congressional policy in the enforcement of the Constitution. The decision was a matter of judicial implication. Since then, it has been frequently applied, and we stoutly adhere to it. But the immediate question is whether the basic right to protection against arbitrary intrusion by the police demands the exclusion of logically relevant evidence obtained by an unreasonable search and seizure because, in a federal prosecution for a federal crime, it would be excluded. As a matter of inherent reason, one would suppose this to be an issue as to which men with complete devotion to the protection of the right of privacy might give different answers. (Texto original) Estados Unidos. Suprema Corte. Wolf v. Colorado, 1949, p. 28. 
Estados seriam responsáveis por materializar a aplicação da XIV Emenda nos respectivos territórios ${ }^{36,37,38}$.

O voto dissidente defendeu a necessidade da doutrina da exclusão de provas ilícitas, tendo em vista a decisão de Weeks, e, ainda, apresentou argumentação mais expansiva em relação à necessidade de se aplicar essa doutrina de forma vinculativa às cortes estaduais. O Juiz Clark afirmou que:

O atalho ignóbil visando a condenação pelo Estado tende a destruir todo o sistema de restrições constitucionais sobre o qual encontram-se as liberdades do povo. Assim, uma vez que se reconheça que o direito à privacidade, incorporado na IV Emenda é executável contra os estados e, que o direito de estar protegido contra invasões arbitrárias de privacidade por oficiais do Estado é, portanto, de origem constitucional, não poderemos mais permitir que esse direito permaneça como uma promessa vazia. Visto que ela é aplicável da mesma maneira e que possui os mesmos efeitos que outros direitos fundamentais assegurados pela cláusula do devido processo legal, não podemos mais permitir que ela seja revogável por capricho de qualquer policial que, em nome da aplicação da lei, escolha suspendê-la a seu gosto. (Tradução nossa) ${ }^{39}$

Ainda que indiretamente, a discussão reconheceu o potencial de autonomia da exclusionary rule, isso porque decidiu-se que sua interpretação era possível dissociada à IV Emenda, o que foi essencial para que se vislumbrasse a possibilidade de se aplicar essa doutrina a outros dispositivos constitucionais ${ }^{40}$. Por outro lado, foi também imprescindível para concepção da deterrence of police misconduct ${ }^{41}$ como a única função da exclusionary rule, interpretação que significou grande retrocesso à doutrina.

\section{O ÁPICE DA CURVA ASCENDENTE DAS GARANTIAS PROCESSUAIS: MAPP V. OHIO (1961)}

Em Wolf v. Colorado (1949), a Suprema Corte sustentou que outros remédios poderiam ter efeitos semelhantes à doutrina de Weeks, reforçando a ideia de que a exclusionary rule não era um dispositivo indispensável ao devido processo legal. Porém, a década que separa Wolf(1949) e

\footnotetext{
${ }^{36}$ Nesse sentido, o voto condutor teve como base outros precedentes, especialmente Palko v. Connecticut, como pode ser notado do trecho a seguir: "Com a finalidade de apurar as restrições que a cláusula do devido processo legal impôs aos estados na aplicação das suas leis criminais, nós seguimos os pontos de vista expressos em Palko v. Connecticut, supra (Tradução nossa)". For purposes of ascertaining the restrictions which the Due Process Clause imposed upon the States in the enforcement of their criminal law, we adhere to the views expressed in Palko v. Connecticut, supra. (Texto original) Estados Unidos. Suprema Corte. Wolf v. Colorado, 1949, p. 26.

${ }^{37}$ Estados Unidos. Suprema Corte. Wolf v. Colorado, 1949, p. 33, 34, 47.

${ }^{38}$ Re, Richard M. The due process exclusionary rule. Harvard Law Review, v. 127, n. 7, p. 1887-1966, 2014, p. 19071910, p. 1934.

${ }^{39}$ The ignoble shortcut to conviction left open to the State tends to destroy the entire system of constitutional restraints on which the liberties of the people rest. Having once recognized that the right to privacy embodied in the Fourth Amendment is enforceable against the States, and that the right to be secure against rude invasions of privacy by state officers is, therefore, constitutional in origin, we can no longer permit that right to remain an empty promise. Because it is enforceable in the same manner and to like effect as other basic rights secured by the Due Process Clause, we can no longer permit it to be revocable at the whim of any police officer who, in the name of law enforcement itself, chooses to suspend its enjoyment. (Texto original) Estados Unidos. Suprema Corte. Wolf v. Colorado, 1949, p. 41.

${ }^{40}$ Commack, Mark E. The rise and the fall of the exclusionary rule in United States. The American Journal of Comparative Law, v. 58, p. 631-658, 2010.

${ }^{41}$ Segundo Estrampes (Manuel Miranda. La prueba ilícita: la regla de exclusion probatoria y sus excpeciones. Revista Catalana de Seguretat, 2010, p. 134), são razões pragmáticas que fundamentam a exclusionary rule, uma vez que tem como objetivo evitar condutas ilícitas na obtenção de provas (deterrence of police misconduct).
} 
Mapp (1961) demonstrou a falsidade desse argumento. Neste julgamento, o voto condutor do Juiz Clark iniciou com uma ressalva em relação às consequências de Wolf para jurisprudência das cortes estaduais:

Enquanto, em 1949, antes do caso Wolf, quase dois terços dos Estados se opunham ao uso da regra de exclusão, agora, apesar do caso Wolf, mais da metade destes desde que passaram a adotá-la por própria decisão legislativa ou judicial, adotaram ou seguiram, totalmente ou parcialmente, à sentença em Weeks. (...). Significativamente, entre os que agora seguem a sentença, a Califórnia, de acordo com a sua mais alta Corte, foi obrigada a chegar a essa conclusão visto que outras soluções não conseguiram de maneira alguma garantir o cumprimento das disposições constitucionais. ${ }^{42}$

A hipótese levantada em Wolf foi respondida de forma diversa em Mapp v. Ohio ${ }^{43}$. O Juiz Clark, responsável pelo voto dissidente em Wolf, foi quem relatou o caso de Dollre Mapp. A nova decisão foi tomada sob a presidência do Juiz Earl Warren, período marcado pela efetivação de direitos civis, a Warren 's court. ${ }^{45}$ A exclusão das provas ilícitas foi reconhecida como medida processual penal definida constitucionalmente pela Suprema Corte e aplicável à violação de outros dispositivos da Constituição americana em razão de sua carga normativa autônoma. ${ }^{46}$ Os precedentes Massiah v. United States (1964) e Miranda v. Arizona (1966) complementaram os novos desdobramentos da doutrina de Weeks apontados em Mapp. No primeiro caso, aplicou-se a regra de exclusão a provas produzidas em razão da ausência de defesa constituída durante confissões indiretas (gravações em cooperação por um coautor), valendo-se, para tanto, a VI

${ }^{42}$ While, in 1949, prior to the Wolf case, almost two-thirds of the States were opposed to the use of the exclusionary rule, now, despite the Wolf case, more than half of those since passing upon it, by their own legislative or judicial decision, have wholly or partly adopted or adhered to the Weeks rule. See Elkins v. United States, 364 U.S. 206, Appendix, pp. 224-232 (1960). Significantly, among those now following the rule is California, which, according to its highest court, was compelled to reach that conclusion because other remedies have completely failed to secure compliance with the constitutional provisions. (Texto original) Estados Unidos. Suprema Corte. Mapp v. Ohio, 1961, p. 651 .

${ }^{43}$ Dollre Mapp era funcionária em casa de apostas ilegais. Em 23/03/1957, policiais do distrito de Cleveland, Ohio, receberam uma denúncia anônima de que Virgil Ogletree, que era procurado por ser suspeito de explodir a casa de apostas de um de seus rivais estaria escondido na casa de Dollre Mapp. Além do suspeito, a denúncia afirma ainda que seria possível encontrar materiais relacionados à casa de jogos de apostas ilegais.

Atendendo a denúncia, três policiais do distrito foram à casa de Dollre Mapp e pediram para entrar, mas a proprietária, depois de consultar seu advogado, não franquiou o acesso dos policiais sem um mandado de busca e apreensão. Depois da negativa, dois policiais deixaram o local, e outro permaneceu vigiando a casa do outro lado da rua.

Três horas depois, quatro viaturas com vários policiais chegaram na casa de Dollre Mapp, bateram na porta, e ela não atendeu a porta. Posteriormente, eles arrombaram a porta e forçaram a entrada na casa, diante desta situação, a proprietária pediu para ver o mandado de busca e lhe foi mostrada um papel, o qual ela tomou de um dos policias e o guardou junto a seu corpo. Os policias tomaram os papéis à força de Dollre e não permitiram que posteriormente seus advogados tivessem acesso ao referido mandado. Durante a busca no segundo andar da casa, Dollre Mapp foi algemada por se comportar de forma beligerante, posteriormente Ogletree, o suspeito, foi encontrado na casa.

Entretanto, Dollre Mapp foi, ainda, presa porque também foram encontrados utensílios para jogos de apostas, uma pistola e livros de pornografia em seus pertences. Ocorre que o papel mostrado à proprietária da casa não era um mandado, foi só um subterfúgio dos policiais para entrarem na casa de Dollre, o que foi comprovado durante a instrução processual, uma vez que tal documento não foi juntado aos autos. Já na Suprema Corte, o promotor de Cleveland, quando da sentença, enumerou cautelosamente os fatos para confirmar a inexistência do mandado. Estados Unidos. Suprema Corte. Mapp v. Ohio, 1961, p. 644.

${ }^{44} \mathrm{Re}$, Richard M. The due process exclusionary rule. Harvard Law Review, v. 127, n. 7, p. 1887-1966, 2014, p. $1907-$ 1910, p. 1934.

${ }^{45}$ Commack,Mark E. The rise and the fall of the exclusionary rule in United States. The American Journal of Comparative Law, v. 58, 2010, p. 632-633.

${ }^{46}$ Commack, Mark E. The rise and the fall of the exclusionary rule in United States. The American Journal of Comparative Law, v. 58, 2010, p. 633. 
Emenda que prevê o direito à presença de advogado. Em Miranda, o direito à não autoincriminação da V Emenda foi utilizado para que se excluíssem os efeitos de uma confissão forçada, na qual o acusado não foi informado dos seus direitos constitucionais e sequer tinha conhecimento dos termos da investigação

A vinculação das cortes estaduais era uma consequência lógica, segundo o voto condutor do Juiz Clark:

Reconhecendo-se que o direito à privacidade, incorporado na IV Emenda é executável contra os estados e, que o direito de estar protegido contra invasões arbitrárias de privacidade por oficiais do Estado é portanto, de origem constitucional, não poderemos mais permitir que esse direito permaneça como uma promessa vazia. Visto que ela é aplicável da mesma maneira e que possui os mesmos efeitos que outros direitos fundamentais assegurados pela cláusula do devido processo legal, não podemos mais permitir que ela seja revogável por capricho de qualquer policial que, em nome da aplicação da lei, escolha suspender o seu exercício. ${ }^{47}$

Essa decisão significou, na trajetória interpretativa da doutrina de Weeks, o ápice de sua amplitude, com o reconhecimento de que doutrina da exclusionary rule era um direito constitucional e com a submissão das cortes estaduais a esse entendimento.

\section{A REDUÇÃO DA DOUTRINA DA EXCLUSÃO A UMA TEORIA INIBITÓRIA, O INÍCIO DO PROCESSO DE DESCONSTITUCIONALIZAÇÃO: CALANDRA V. UNITED STATES (1974)}

Em Calandra v. United States (1974), as posições firmadas em Mapp perderam a maioria na Suprema Corte e, a despeito de toda ascensão que este precedente proporcionou, a jurisprudência regride quanto ao reconhecimento do caráter constitucional da exclusionary rule. Categoricamente, a Suprema Corte concluiu que a regra da exclusão não seria inerente à existência da IV Emenda ${ }^{48}$, provocando sua desconstitucionalização. Isso possibilitou diversos retrocessos na história dos direitos fundamentais, especialmente no que tange à liberdade dos cidadãos, operando um efeito diametralmente contrário ao de Mapp v. Ohio (1961). ${ }^{49}$

Segundo a posição da maioria, a única função da doutrina de Weeks seria inibir a conduta dos agentes de polícia, ou seja, seria uma teoria de accountability dos atos destes. Assim, a regra deixou de ser um direito constitucional para garantir o devido processo legal em procedimentos processuais, garantia stricto sensu, e transformou-se em uma teoria sobre a inibição de condutas dos agentes do estado, que agem em desconformidade com os procedimentos processuais, o que dependeria da valoração da necessidade de sua aplicação em cada caso. ${ }^{50}$

Dessa forma, a Suprema Corte passou a discutir a necessidade da exclusão de provas tendo em vista suposta violação direta à doutrina de Weeks, e não mais se teria havido violação

\footnotetext{
${ }^{47}$ Having once recognized that the right to privacy embodied in the Fourth Amendment is enforceable against the States, and that the right to be secure against rude invasions of privacy by state officers is, therefore, constitutional in origin, we can no longer permit that right to remain an empty promise. Because it is enforceable in the same manner and to like effect as other basic rights secured by the Due Process Clause, we can no longer permit it to be revocable at the whim of any police officer who, in the name of law enforcement itself, chooses to suspend its enjoyment. (Texto original) Estados Unidos. Suprema Corte. Mapp v. Ohio, 1961, p. 660.

${ }^{48}$ Estados Unidos. Calandra v. United Stated, 1974, p. 354, 355, 364.

${ }^{49}$ Clancy, Thomas K. The fourth amendment`s exclusionary rule as a right. Ohio State Journal of Criminal law, v. 10, 2012, p.367.

${ }^{50}$ Clancy, Thomas K. The fourth amendment`s exclusionary rule as a right. Ohio State Journal of Criminal law, v. 10, 2012, p.368.
} 
aos direitos fundamentais do cidadão, garantidos por diversos dispositivos constitucionais ${ }^{51}$. No voto condutor do Juiz Powell, a exclusionary rule passa a ser necessária somente quando a exclusão de evidências for o remédio mais eficiente para inibir que os policias reiterem determinado comportamento:

A aplicação da regra tem se restringido à aquelas situações em que seu mandamento corretivo seja o método mais eficaz à disposição. O processo compensatório implícito nessa abordagem está expresso nos moldes do requerimento proposto. Assim, a invocação da exclusionary rule tem se limitado às situações onde o Governo deseja utilizar tais evidências (ilicitamente obtidas) para incriminar vítimas de uma busca ilegal. (Tradução nossa) ${ }^{52}$

Com base nestes critérios, que são claramente subjetivos - efetividade e necessidade -, a pergunta sobre "quando" se deveria proceder à exclusão de provas ilícitas se torna extremamente relevante. Para "medir" a eficiência da aplicação desta regra, a Suprema Corte criou o based balancing test $t^{53}$ que, em tese, leva em consideração dois critérios: a eficácia da inibição e os custos para o Estado da exclusão de provas ilícitas. ${ }^{54}$ Nota-se, portanto, o deslocamento do eixo interpretativo, pois se julga a eficiência da exclusão ao invés da violação aos direitos fundamentais, ideia anteriormente central.

A perspectiva adotada na decisão, segundo a qual a regra da exclusão visava exclusivamente inibir condutas de oficiais da polícia, apesar de fazer parte do escopo de criação da exclusionary rule em Weeks, era simplista em relação ao histórico de direitos firmados pela Suprema Corte. A doutrina de Weeks perde seu caráter de obrigatoriedade, passando a ser um mandamento de prudência dentro do ordenamento jurídico estadunidense ${ }^{55}$, pois a Corte estabeleceu, ainda, que a necessidade de seu uso dependeria da tentativa de emprego direto da evidência para incriminar o cidadão, retirando-se, dessa forma, as violações indiretas à doutrina do rol de ilegalidades. Logo, reduziu subjetivamente e objetivamente a utilização da regra: válida somente para as polícias e para o uso direto da evidência no contexto fático probatório. ${ }^{56}$

Calandra foi o precedente que abriu caminho para diversos retrocessos. Incluiu na discussão argumentos meta-jurídicos à aplicação da exclusionary rule, uma vez que se passa a analisar os custos sociais para o processo que a exclusão de evidências poderia trazer, isto é, a doutrina de Weeks é atacada com base em argumentos de ordem pública: inibir a conduta policial se tornou mais importante que a garantia dos direitos fundamentais do cidadão ao devido processo legal. A exclusionary rule perde seu status constitucional, e, em decorrência disso, deixa de ser

\footnotetext{
${ }^{51}$ Estados Unidos. Calandra v. United States, 1974, p. 366.

${ }^{52}$ The application of the rule has been restricted to those areas where its remedial objectives are thought most efficaciously served. The balancing process implicit in this approach is expressed in the contours of the standing requirement. Thus, standing to invoke the exclusionary rule has been confined to situations where the Government seeks to use such evidence to incriminate the victim of the unlawful search. (Texto original) Estados Unidos. Calandra v. United States, 1974, p. 348.

${ }^{53}$ Segundo Nestor Távora e Rosmar Rodrigues Alencar (2017), A proporcionalidade ganhou desenvoltura e disciplina na jurisprudência e doutrina alemãs, adaptada ao Direito judicial estadunidense como teoria da proporcionalidade (balancing test), funcionando como regra de exclusao a inadmissibilidade das provas ilícitas, quando, sopesando o caso concreto, chegue-se a conclusão que a exclusão da prova ilícita levaria a absoluta perplexidade e evidente injustiça.

${ }^{54}$ Clancy, Thomas K. The fourth amendment`s exclusionary rule as a right. Ohio State Journal of Criminal law, v. 10, 2012, p.370.

55 “prudential [rule] rather than constitutionally mandated.” Estados Unidos. Calandra v. United States, 1974 , p. 348. (texto original).

${ }^{56} \mathrm{O}$ dispositivo deste acórdão manteve decisão, tomada em procedimento de júri, a respeito da possibilidade de se fazer perguntas para testemunha cujo objeto seria um fato já considerado ilícito, ou seja, permitiu derivar prova de fato ilícito. Estados Unidos. Calandra v. United States, 1974, p. 342-355.
} 
um direito, em regra, oponível ao Estado quando de violações derivadas de buscas ilegais sob o fundamento da IV Emenda. ${ }^{57}$

$\mathrm{Na}$ conclusão do voto condutor do Juiz Powell, que foi seguido por cinco de seus pares, a perda do direito constitucional resta evidenciada no fato de que os efeitos de uma busca, considerada em juízo ilícita, não fazem mais surgir o direito constitucional à exclusão de procedimentos derivados desta:

No contexto habitual de um julgamento criminal, o acusado tem o direito à supressão de provas obtidas através de buscas ilegais, e, também, do uso derivado desta. A proibição do uso da regra deve atingir este uso derivado, uma vez que seu objetivo é deter má conduta policial. No contexto de um grand jury proceeding ${ }^{58}$, acreditamos que o dano a essa instituição a partir da extensão sem precedentes da regra de exclusão instados pelo entrevistado supera o benefício de qualquer possível efeito dissuasor incremental. ${ }^{59}$

Enfim, o debate sobre a situação concreta (o caso) deixa de ser a pergunta sobre a existência de um direito fundamental e sua violação. Ao invés disso, ele foi deslocado em direção à necessidade de considerar o uso de provas que foram obtidas em decorrência da violação de um direito que é reconhecido como direito fundamental. $\mathrm{O}$ caso (a incidência ou não do direito) é transformado num debate sobre o que deve ser feito quando esse direito é violado. O que significa, na prática, desconstitucionalizar a regra da exclusão e, na mesma direção, fragilizar ou negar o direito violado.

\section{A AMEAÇA DIRETA À DOUTRINA DA EXCLUSÃO: HUDSON V. MICHIGAN (2006)}

Calandra v. United States foi de extrema relevância para a atual interpretação da regra da exclusão, pois criou toda uma diferenciação na maneira pela qual se deveria utilizar a doutrina de Weeks, tendo em vista que a Suprema Corte passou a utilizar o teste de eficiência prática da exclusionary rule a casos concretos. Os retrocessos em relação aos direitos protegidos pela doutrina se fizeram visíveis em novos precedentes.

Hudson v. Michigan é emblemático. Questionava-se, na ocasião, a possibilidade de se excluir evidências obtidas durante uma busca e apreensão com mandado judicial válido, mas que os policiais não deram, segundo a defesa, tempo hábil para que o morador abrisse a porta a

\footnotetext{
${ }^{57}$ Estados Unidos. Calandra v. United States, 1974, p. 350-355.

${ }^{58}$ Um grand jury é composto, em regra, por 23 membros reunidos em segredo. Tem a função de, em diversas oportunidades, durante determinado espaço de tempo, apreciar as provas apresentadas apenas pela acusação, sem a presença das partes e decidir se há indícios suficientes de que o suspeito tenha praticado um crime.

Se a decisão for afirmativa, ela é expressa por escrito em um instrumento chamado bill ofindictment ou true bill. Como resultado, de suspeito, o indivíduo passa a réu e é levado à presença de um Juiz durante uma audiência denominada arraignment para declarar-se culpado ou inocente

Dependendo da resposta, o acusado é levado a julgamento por júri. O julgamento é realizado por um corpo de jurados menor, - normalmente, por 6 a 12 jurados, que compõem o chamado petit jury (júri ou pequeno júri), perante o qual, ao contrário do que ocorre no grand jury, comparecem ambas as partes e seus respectivos representantes.

${ }^{59}$ This case presents the question whether a witness summoned to appear and testify before a grand jury may refuse to answer questions on the ground that they are based on evidence obtained from an unlawful search and seizure. The issue is of considerable importance to the administration of criminal Justice. (Texto original) Estados Unidos. Calandra v. United States, 1974, p. 339.
}

Revista de Direito Brasileira | Florianópolis, SC | v. 27 | n. 10 | p.216-240 | Set./Dez. 2020 
autoridades policiais, desrespeitando-se dessa forma a knock and announce doctrine ${ }^{60,61,62}$. Diante das decisões anteriores, o teor desta decisão não foi uma surpresa. ${ }^{63}$ A relevância do precedente repousa, essencialmente, nas afirmações proferidas pelo Juiz condutor do voto. O Juiz Scalia fez declarações contundentes contra a necessidade de previsão jurisprudencial que estipulasse a exclusão de evidências de um processo judicial. Pela primeira vez na história da Suprema Corte, um magistrado se posicionou de forma tão incisiva, atacando diretamente o fundamento de existência da exclusionary rule, que já estava numa condição de aplicabilidade reduzida. ${ }^{64}$

O Juiz Scalia parte do caráter inibitório da doutrina de Weeks e, desde aí, ${ }^{65}$ passa a questionar a validade da exclusionary rule com este efeito inibitório. Ao mesmo tempo, destaca que os custos para a sociedade com a exclusão de provas de um processo seriam altíssimos ${ }^{66,67}$.

A supressão de provas sempre foi o nosso último recurso, não o nosso primeiro impulso. A exclusionary rule (regra de exclusão) gera custos sociais substanciais, que às vezes inclui deixar um culpado livre e o perigo à solta. Estamos, portanto, sendo cautelosos contra a sua expansão (exclusionary rule), e, temos enfatizado repetidamente que o custo oneroso dos seus objetivos em buscar a verdade e aplicar a lei apresenta um grande obstáculo para aqueles que pressionam a sua aplicação. Nós temos rejeitado a aplicação indiscriminada da exclusionary rule, e mantivemos a sua aplicação somente nas situações em que seu mandamento corretivo seja o método mais eficaz à disposição, isto, é, onde seus benefícios de dissuasão superem o seu custo social substancial.

Nem sempre falamos de forma tão cautelosa. Expansivamente como dito em Mapp, por exemplo, sugeriu uma ampla margem para a exclusionary rule. Porém, há muito tempo temos rejeitado tal abordagem (Tradução nossa).

Haveria, segundo o magistrado, outros métodos eficazes para o controle dos atos dos policiais, métodos de accountability menos custosos para o Estado. ${ }^{68}$ Além disso, a polícia estadunidense já não poderia ser considerada a mesma da década de 1960, pois possuía maior

\footnotetext{
${ }^{60}$ Impunha, enquanto procedimento processual vinculado à IV emenda, à autoridade policial o dever de bater na porta, anunciar sua presença e aguardar um período razoável antes de entrar no domicílio do acusado. Esta doutrina faz parte das decisões da Suprema Corte que tentam garantir mais privacidade aos cidadãos.

${ }^{61}$ Suprema Corte. Estados Unidos. Hudson v. Michigan, 2006, p. 3.

${ }^{62}$ Clancy, Thomas K. The fourth amendment`s exclusionary rule as a right. Ohio State Journal of Criminal law, v. 10, p. 357-391, 2012.

${ }^{63}$ Sklansky, David Alan. Is the exclusionary rule obsolete? Ohio State Journal of Criminal Law, v. 5, n. 567, p. 568, 2008

${ }^{64}$ Clancy, Thomas K. The fourth amendment`s exclusionary rule as a right. Ohio State Journal of Criminal law, v. 10, p. 357-391, 2012.

${ }^{65}$ Estados Unidos. Hudson v. Michigan, 2006, p. 8.

${ }^{66}$ Sklansky, David Alan. Is the exclusionary rule obsolete? Ohio State Journal of Criminal Law, v. 5, n. 567, p. 568, 2008.

${ }^{67}$ Suppression of evidence . . has always been our last resort, not our first impulse. The exclusionary rule generates "substantial social costs," which sometimes include setting the guilty free and the dangerous at large. We have therefore been "cautio[us] against expanding" it, and "have repeatedly emphasized that the rule's 'costly toll' upon truth-seeking and law enforcement objectives presents a high obstacle for those urging [its] application[.]" We have rejected "[i]ndiscriminate application" of the rule, and have held it to be applicable only "where its remedial objectives are thought most efficaciously served," that is, "where its deterrence benefits outweigh its 'substantial social costs[.] "'We did not always speak so guardedly. Expansive dicta in Mapp, for example, suggested wide scope for the exclusionary rule. But we have long since rejected that approach. (Texto original) Suprema Corte. Hudson v. United States, 2006, p. 4.

${ }^{68}$ Sklansky, David Alan. Is the exclusionary rule obsolete? Ohio State Journal of Criminal Law, v. 5, n. 567, p. 568, 2008
} 
treinamento, era mais profissionalizada, e tinha seus atos muito mais controlados direta e indiretamente pela Administração ${ }^{69}$ :

Outro acontecimento no último meio século que impede as violações dos direitos civis é o crescente profissionalismo das forças policiais, incluindo uma nova ênfase na disciplina policial interna. Ainda mesmo nos anos 1980, nós consideramos apropriado "assumir" que o comportamento policial ilegal seria "tratado apropriadamente" pelas autoridades, mas agora temos evidências crescentes de que as forças policiais em todo os Estados Unidos levam a sério os direitos constitucionais dos cidadãos. Houve "amplas reformas na educação, treinamento e supervisão dos policiais".

É importante neste ponto reforçar: a discussão proposta sobre a desnecessidade da doutrina de Weeks repousa justamente no fato de que, a partir de Calandra v. United States, esta regra deixou de ser encarada como um direito constitucional. Ora, de forma alguma, os juízes daquela Suprema Corte argumentariam abertamente que um direito constitucional fosse desnecessário, isto é, o pano de fundo desta argumentação baseia-se na desconstitucionalização da regra analisada. Portanto, foi aquele precedente que permitiu transformar a regra da exclusão num método obsoleto, de eficácia duvidosa e com custos altos para a persecução penal do Estado, e não o contrário. ${ }^{70} 71$

As considerações do Juiz Scalia foram tão anormais que um de seus quatro pares, que concordou com a decisão em Hudson, abriu dissidência justamente sobre as considerações do voto condutor. O Juiz Kennedy afirmou que "o permanente uso da regra de exclusão de provas ilícitas, como estabelecida e definida por nossos precedentes, não está em dúvida" ${ }^{72}$. Assim, é possível concluir que cinco juízes da Suprema Corte não sustentavam que a exclusionary rule fosse uma teoria sem razão de existir. ${ }^{73}$ Até este momento na jurisprudência da Suprema Corte não se havia relativizado a doutrina de Weeks em relação à necessidade de mandado judicial fundado na causa provável do cometimento de crime. Entretanto, isto viria a ocorrer posteriormente.

\section{AS INTERPRETAÇÕES DECORRENTES DO PROCESSO DE DESCONSTITUCIONALIZAÇÃO DA REGRA DA EXCLUSÃO E O ATAQUE AOS DIREITOS EXPLÍ́CITOS NA IV EMENDA: HERRING V. UNITED STATES (2009)}

Em Herring v. United States, a Suprema Corte pela primeira vez aplicou a exceção da prova ilícita de boa-fé a um caso em que a polícia não detinha mandado de busca e apreensão válido. ${ }^{74}$ Anteriormente, em United States v. Leon, foi decidido que as evidências (resultantes de busca originada em mandado expedido por juízo, mas posteriormente reconhecido como nulo)

\footnotetext{
${ }^{69}$ Another development over the past half-century that deters civil-rights violations is the increasing professionalism of police forces, including a new emphasis on internal police discipline. Even as long ago as 1980 we felt it proper to "assume" that unlawful police behavior would "be dealt with appropriately" by the authorities but we now have increasing evidence that police forces across the United States take the constitutional rights of citizens seriously. There have been "wide-ranging reforms in the education, training, and supervision of police officers. (Texto original) Suprema Corte. Hudson v. United States, 2006, p. 14.

${ }^{70}$ Sklansky, David Alan. Is the exclusionary rule obsolete? Ohio State Journal of Criminal Law, v. 5, n. 567, p. 568, 2008

${ }^{71}$ Sklansky, David Alan. Is the exclusionary rule obsolete? Ohio State Journal of Criminal Law, v. 5, n. 567, p. 568, 2008

72 "the continued operation of the exclusionary rule, as settled and defined by our precedents, is not in doubt." (Texto original) Suprema Corte. Hudson v. United States, 2006, p. 1.

${ }^{73}$ Sklansky, David Alan. Is the exclusionary rule obsolete? Ohio State Journal of Criminal Law, v. 5, n. 567, p. 568, 2008

${ }^{74}$ Henning, Anna C. Rule in fourth amendment cases. Congressional Research Service, 2009, p. 5.
} Revista de Direito Brasileira | Florianópolis, SC | v. 27 | n. 10 | p.216-240 | Set./Dez. 2020 
não deveriam ser excluídas do processo, uma vez que os policiais teriam agido sob fundada confiança ${ }^{75}$ Dessa forma, considerou-se que não haveria razão para a exclusão das provas quando o erro na expedição do mandado não fosse responsabilidade dos policiais. ${ }^{76}$

Entretanto, em Herring $v$. United States, a exceção criada neste precedente adquire novas proporções, uma vez que foi utilizado num contexto de ausência de decisão judicial autorizadora inicialmente válida. No caso, Benne Herring foi em seu veículo à Coffee County, Estado do Alabama, para verificar informações a respeito de uma caminhonete. Nesta situação, o investigador, Mark Anderson, tomou informações com o departamento de polícia da cidade sobre Herring. $\mathrm{O}$ investigador foi informado que havia um mandado de prisão em desfavor de Benne em uma cidade vizinha, Dale County. Mark Anderson executou a prisão. Ocorre que, quinze minutos após a prisão, o funcionário de Dale County retornou o contato e informou que havia cometido um erro, pois o mandado tinha sido revogado há cinco meses. Tarde demais. Durante a prisão, foram encontradas armas proibidas e metanfetamina na referida caminhonete.

A Suprema Corte decidiu que a exclusionary rule não deveria ter sido aplicada ao caso, revertendo as decisões de primeira e segunda instância. Para tanto, criou um novo critério para autorizar a (não) aplicação da referida regra, isto é, a conduta dos policiais deveria ser deliberadamente ilícita e suficientemente culpável para que se pudesse acionar o gatilho da regra de exclusão das provas. Inverteu-se, desse modo, o referencial de aplicação da doutrina da exclusão de provas ilícitas. ${ }^{77}$ A ilegalidade ensejaria exclusão de evidências quando "independentemente de um policial razoavelmente bem treinado, diante de todas as circunstâncias, pudesse ter reconhecido a ilegalidade da busca" ${ }^{78}$. A conduta só seria passível de excluir as provas se, no caso concreto, o policial potencialmente soubesse da ilicitude da busca. ${ }^{79}$

Neste sentido, somente condutas altamente reprováveis, nas quais fosse clara a culpa do policial, deveriam ser objeto de controle, utilizando-se assim de um referencial de responsabilidade administrativa para o uso da regra. Mais uma vez, evidencia-se o deslocamento do debate acerca das razões de aplicabilidade da exclusionary rule, que não mais repousa sobre o fundamento do controle do exercício arbitrário da força pelo Estado, para que dessa forma, se protegesse potencialmente direitos constitucionais, individualmente considerados para as diversas aplicações possíveis da doutrina de Weeks. A responsabilidade do Estado, personificado em seus agentes, quando da violação de direitos fundamentais dos cidadãos, deixa de ser objetiva. Logo, a Suprema Corte consolida a decisão de Hudson v. Michigan a respeito da desconstitucionalização da exclusionary rule. ${ }^{80}$

\section{AS DIFERENÇAS SISTEMÁTICAS DO DEBATEDO DEBATE DA DESCONSTITUCIONALIZAÇÃO DA VEDAÇÃO À PROVA ILÍCITA}

No cenário estadunidense, a tensão entre constitucionalização versus desconstitucionalização da regra da exclusão não é um consenso entre os estudiosos das decisões da Corte Constitucional. Provavelmente, porque o embate entre o reconhecimento de uma posição é também um embate discursivo sobre o que se pretende ver construído como direito constitucional numa próxima decisão.

\footnotetext{
${ }^{75}$ Henning, Anna C. Rule in fourth amendment cases. Congressional Research Service, 2009, p. 3.

${ }^{76}$ McDonald, Marc. W. The good faith exception to the exclusionary rule: United States v. Leon and Massachusetts v. Sheppard. Boston College Law Review, v. 27, n. 609, p. 610, 1986.

${ }^{77}$ Henning, Anna C. Rule in fourth amendment cases. Congressional Research Service, 2009, p. 6.

78 "' whether a reasonably well trained officer would have known that the search was illegal' in light of 'all the circumstances",' (Texto original). Suprema Corte. Leon v. United States, 1984, p. 922.

${ }^{79}$ Estados Unidos. Herring v. United States, 2009, p. 4-5.

${ }^{80}$ Henning, Anna C. Rule in fourth amendment cases. Congressional Research Service, 2009, p. 6.
} Revista de Direito Brasileira | Florianópolis, SC | v. 27 | n. 10 | p.216-240 | Set./Dez. 2020 
Craig Bradley, por exemplo, ao perguntar "is the exclusionary rule dead?", responde negativamente. Diante da análise de Hudson v. Michigan, Herring v. United States e David v. United States sugere que a Suprema Corte não eliminou a regra de exclusão, mas está construindo o entendimento de que as evidencias somente devem ser excluídas em casos de negligência substancial, ou seja, "when negligence has substantially interfered with a suspect's privacy rights, such as through an illegal arrest or and illegal search of his car or house". ${ }^{81} 82$ A Corte teria se afastado da exclusão automática de provas na análise concreta dos casos, porém, não apresentou, ainda, critérios definidos para tal supressão. Não se sabe se os julgamentos deveriam utilizar uma regra objetiva baseada no comportamento hipotético de um policial razoável ou uma regra subjetiva pautada pela culpabilidade dos policiais no caso em questão. ${ }^{83}$

Jeffry Gittins, por sua vez, dá continuidade ao ataque à regra da exclusão em "Excluding the Exclusionary Rule: Extending the Rationale of Hudson v. Michigan to Evidence Seized During Unauthorized Nighttime Searches", defendendo que, em Weeks v. United States, a Corte teria consolidado, de modo problemático, um contraponto à aplicação geral da common law rule norteamericana que toda prova é admissível, independentemente do modo como for obtida. Entretanto, nas decisões mais recentes, a Corte, ao modificar seu entendimento sobre a necessidade de um policial anunciar sua chegada ("knock-and-announce rule") - direito que ela mesma havia construído em oposição àquele direito consuetudinário aplicado nos Estados da Federação -, evidenciou a possibilidade de eliminar também a proibição de impedimento de buscas durante a noite, regra criada, de igual modo, pela própria Corte ao interpretar o sentido de privacidade da IV Emenda ${ }^{84}$

Portanto, o embate discursivo ora se apresenta como reconstrutor de possibilidades de limitação ora como validação de futuras supressões de direitos.

A trajetória estadunidense da doutrina da regra da exclusão permite constatar a consolidação de um debate público sobre as garantias processuais stricto sensu, as quais, desde um ponto de vista garantista, requerem da jurisdição procedimentos para garantir materialmente o devido processo legal, próprio de um sistema acusatório, com a observância do axioma nullum indicium sine accusatione, sine probatione et sine defensione. ${ }^{85}$ Portanto, a licitude dos meios de produção de provas configura como um pressuposto para maximização desses axiomas englobando o sentido de devido processo legal -, ou seja, o reconhecimento da ilicitude requerida constitucionalmente é inerente ao processo penal num Estado Democrático de Direito. E isso deveria ser válido mesmo que o ordenamento seja silente, como é o caso dos Estados Unidos, ou expresso, como no caso do Brasil.

Todavia, presencia-se, embora em contexto de tradição jurídica distinta, um ataque contínuo à regra da exclusão. ${ }^{86} \mathrm{~A}$ propósito, em 2016, o Ministério Público Federal, valeu-se de precedentes, em especial de Leon v. United States, analisando-os isoladamente dentro do contexto da jurisprudência da Suprema Corte dos Estados Unidos, para propor, mediante assinaturas

\footnotetext{
${ }^{81}$ Quando a ação negligente interferiu substancialmente com os direitos de privacidade do suspeito, como, por exemplo, em uma prisão ilegal ou em uma busca legal de sua casa ou carro. (Tradução nossa).

${ }^{82}$ Bradley, Craig. Is the exclusionary rule dead? The Journal of Criminal Law and Criminology, Vol. 102, No. 1, pp. 1-23. Chicago: Northwestern University School of Law, Winter 2010, p. 1.

${ }^{83}$ Bradley, Craig. Is the exclusionary rule dead? The Journal of Criminal Law and Criminology, Vol. 102, No. 1, pp. 1-23. Chicago: Northwestern University School of Law, Winter 2010, p. 1.

${ }^{84}$ Gittins, Jeffry. Excluding the Exclusionary Rule: Extending the Rationale of Hudson v. Michigan to Evidence Seized During Unauthorized Nighttime Searches. Brigham Young University Law Review, Vol. 2007, N. 2, p. 451-481, 2007.

${ }^{85}$ Ferrajoli, Luigi. Direito e razão: teoria do garantismo penal. São Paulo: RT, 2002.

${ }^{86}$ BADARÓ, Gustavo. As propostas de alteração do regime de provas ilícitas no processo penal. Boletim 277 do Instituto Brasileiro de Ciências Criminais, 2015.
} 
populares, as intituladas 10 medidas contra a corrupção ${ }^{87}$, incluindo entres estas a aplicação da exceção de prova ilícita de boa-fé, que é diametralmente oposta ao artigo $5^{\circ}$, LVII, da Constituição Federal e cujo desentranhamento é regulado pelo artigo 157 do Código de Processo Penal. Além disso, essa norma é integrante dos direitos e garantias fundamentais, não sujeitos a supressão sequer por emenda constitucional nos termos do art. $60, \S 4^{\circ}{ }^{88}$ Entretanto, presencia-se um debate aberto sobre a relativização da regra da exclusão da prova ilícita, encontrando-se decisões judiciais que pretendem justificar essa posição com fundamento na necessidade de combate à criminalidade.

De fato, a proposta de relativização da regra da exclusão já era defendida pelos partidários da Teoria do Garantismo Penal Integral ${ }^{89}$. Segundo estes, seria necessário olhar para a problemática processual penal não mais de uma perspectiva hiperbólica, sendo indispensável valorar o interesse público e direitos coletivos para a garantia de verdade, ou seja, diante da previsão de direitos coletivos e individuais, para que se tenha verdadeiramente eficiência e segurança, seria indispensável introduzir dentro da relação processual os interesses coletivos, interpretados, a bem da verdade, segundo a lógica punitivista do eficientismo penal ${ }^{90}$. Mais do que isso, descontextualizando a origem da exceção da prova ilícita da boa-fé nos Estados Unidos, que foi possível após a desconstituciolização do apontado remédio constitucional.

Essas propostas sugerem um problema essencial pouco discutido por aqueles que se valem, aparentemente, da "cópia" dos modelos alienígenas em petições, decisões judiciais e propostas públicas de alteração legislativa: a neutralidade e a fidelidade ao contexto de origem dessas propostas. O que esse ato simples de citar a doutrina estrangeira pode, de fato, ocultar sobre o significado daquilo que está sendo debatido? Ao lermos uma decisão da Suprema Corte Americana, estaríamos lendo o sistema constitucional americano, suas tensões institucionais e políticas? O deslocamento do contexto (normativo, institucional e social) poderia provocar uma mudança do sentido originário? Ou ainda, poderia ser uma opção de um sentido, entre os múltiplos sentidos em disputa no contexto de origem? O deslocamento não representaria a criação de um terceiro sentido em relação ao contexto?

Sobre o tema, na tentativa de construir uma genealogia acerca do papel desempenhado pelas traduções no surgimento da Criminologia na América Latina, Mássimo Sozzo traz elementos importantes para o debate. ${ }^{91}$ Ao constatar a apropriação/criação de doutrina estrangeira o autor chama a atenção para o aspecto intrinsecamente "criativo", "interpretativo", envolvido em todo processo de tradução como uma "complexa tecnologia intelectual". 92 A expressão "traduttore traditore" indica a "traição" envolvida em todo processo de "tradução" como exercício culturalmente criativo, interpretativo por excelência. Assim, afasta-se da ideia da tradução como simples "transposição" ou "transplante" neutro, para apresentar "o traduzido" como fruto também do ofício criativo do "tradutor/outro autor". ${ }^{93}$ Daí a tradução como traição (traduttore tradittore),

\footnotetext{
${ }^{87} \mathrm{O}$ projeto de Lei n. 4850/2016 - Projeto de lei e outras proposições - foi proposto ao Congresso pela via de assinatura de populares, em defesa do projeto apresentado por membros do Ministério Público Federal.

${ }^{88}$ Silva, José Afonso. Aplicabilidade das Normas Constitucionais. São Paulo: Editora Malheiros, 2012.

${ }^{89}$ Como visto em: Pelella, Eduardo; Calabrich, Bruno e Fischer, Douglas. Garantismo Penal Integral - $2^{\circ}$ edição: revista, ampliada e atualizada. 2 ed. Salvador/BA: Juspodivm, 2013. 520p.

${ }^{90}$ Sobre a distância entre legalidade e práticas institucionais na América Latina, veja-se: ZAFFARONI, Eugenio Raúl. Em busca das penas perdidas: a perda de legitimidade do sistema penal. Rio de Janeiro: Revan, 1991.

${ }^{91}$ Mássimo Sozzo, como uma "complexa tecnologia intelectual", a ser debatido na parte final do artigo, como visto em Sozzo, Máximo. Tradutore traditore. Traduc-ción, importación cultural e historia del presente de la criminología en América Latina. In: ____ (ed.): Reconstruyendo las criminologías críticas, Ad-Hoc, Buenos Aires, 2006.

${ }_{92}$ Mássimo Sozzo, como uma "complexa tecnologia intelectual", a ser debatido na parte final do artigo, como visto em Sozzo, Máximo. Tradutore traditore. Traduc-ción, importación cultural e historia del presente de la criminología en América Latina. In: ___ _ (ed.): Reconstruyendo las criminologías críticas, Ad-Hoc, Buenos Aires, 2006, p. 379.

${ }^{93}$ Mássimo Sozzo, como uma "complexa tecnologia intelectual", a ser debatido na parte final do artigo, como visto em Sozzo, Máximo. Tradutore traditore. Traduc-ción, importación cultural e historia del presente de la criminología Revista de Direito Brasileira | Florianópolis, SC | v. 27 | n. 10 | p.216-240 | Set./Dez. 2020
} 
tanto naquilo que o autor denomina "tradução em sentido estrito", em que o tradutor surge como um mediador neutro entre o texto original e o traduzido, quanto na "tradução em sentido amplo", levada adiante por "outro autor" que concebe o "traduzido" como um produto intelectual próprio. Para Sozzo, o que interessa é mostrar como os termos criminológicos traduzidos/importados não se mantiveram intocados; ao contrário, fizeram parte de uma "viagem cultural" que os fazia adquirir novas formas, metamorfoseando-os. ${ }^{94}$

Nesse sentido, destacam-se algumas "trajetórias interpretativas" dessas "viagens culturais" que podem ser reconhecidos como casos exemplares de tradução/traição no caso da doutrina da exclusão da prova ilícita. A disjunção entre texto (negativa da doutrina da exclusão) e contexto (sistema constitucional americano ou brasileiro) é essencial para compreender o caráter criativo e traidor das propostas "brasileiras" de adoção da "lógica" consolidada em Herring $v$. United States. Vejamos algumas dessas disjunções.

A Suprema Corte norte-americana deixou de considerar a regra da exclusão como um direito constitucional para considerá-la uma técnica inibitória em 1974 em Calandra v. United States. O Constituinte brasileiro em 1988, conhecendo isso (ou podendo conhecer), adotou a regra da exclusão como um direito fundamental. Logo, fez a escolha de considerar a exclusão como um direito constitucional e consequência lógica da violação dos demais direitos inseridos no art. $5^{\circ}$, sem perquirir sobre finalidades extrajurídicas, tais como a utilidade, a possibilidade de outras técnicas de garantia, a proporcionalidade da medida em relação à pretensão de acusação etc. A comparação com o sistema processual de onde a regra se origina, reforça a clareza contida na afirmação direta do constituinte: LVI - são inadmissíveis, no processo, as provas obtidas por meios ilícitos. ${ }^{95}$

A mesma conclusão pode ser extraída da decisão do Supremo Tribunal Federal nos autos da AP 307 (rel. Min. Ilmar Galvão, j. 13-12-1994, PP - 037, DJ de 10-05-1996) que reconheceu a aplicabilidade da medida aos casos de interceptação telefônica. No caso concreto, a Suprema Corte entendeu pela inadmissibilidade, como prova de laudos de degravação de conversa telefônica e de registros contidos na memória de microcomputador, obtidos por meios ilícitos (art. $5^{\circ}$, LVI, da $\mathrm{CF}$ ); no primeiro caso, tratava-se de gravação realizada por um dos interlocutores, sem conhecimento do outro, tendo sido feita a degravação com inobservância do princípio do contraditório, e utilizada com violação a privacidade alheia (art. $5^{\circ}, \mathrm{X}, \mathrm{da} \mathrm{CF}$ ); e, no segundo caso, por se tratar de microcomputador que, além de ter sido apreendido com violação de domicílio, teve a memória degravada em desrespeito à garantia da inviolabilidade da intimidade das pessoas (art. $5^{\circ}, \mathrm{X}$ e XI, da CF). ${ }^{96}$

A Suprema Corte norte-americana, ao ponderar sobre a desnecessidade da regra da exclusão, no caso Hudson v. Michigan (2006), tinha um argumento de caráter pragmático importante que, muito embora não tenha sido provado, era passível de ser traduzido em dados estatísticos: a polícia americana estava profissionalizada e havia métodos mais eficazes para o seu controle. De fato, sob a influência de um uso minucioso dos pressupostos de Weeks, além da pressão política imediata, as polícias americanas passaram por um processo profundo de modernização, com maior profissionalização e uso de intenso da perícia na determinação da

en América Latina. In: (ed.): Reconstruyendo las criminologías críticas, Ad-Hoc, Buenos Aires, 2006, p. 378-379.

${ }^{94}$ Mássimo Sozzo, como uma "complexa tecnologia intelectual", a ser debatido na parte final do artigo, como visto em Sozzo, Máximo. Tradutore traditore. Traduc-ción, importación cultural e historia del presente de la criminología en América Latina. In: (ed.): Reconstruyendo las criminologías críticas, Ad-Hoc, Buenos Aires, 2006, p. 382.

${ }^{95}$ LOPES JR., Aury. Introdução crítica ao processo penal: fundamentos da instrumentalidade garantista. 3. ed. Rio de Janeiro: Lúmen Juris, 2005.

${ }^{96}$ GOMES FILHO, Antônio Magalhães. Direito à prova no processo penal. São Paulo: Revista dos Tribunais, 1997. TAVORA, N. ; ALENCAR, R. A. R. C. Curso de direito processual penal. 12. ed. Salvador/BA: Juspodivm, 2017. v. 1. 1840p. 
culpabilidade dos acusados. No caso brasileiro, houve tentativa de modernização nos últimos vinte anos, porém, as formas de controle externo e interno têm sido tímidas ou ineficazes. ${ }^{97}$

A Suprema Corte Estadunidense, no processo de desconstitucionalização da regra da exclusão, passou a considerar a responsabilidade do Estado, personificado em seus agentes, quando da violação de direitos fundamentais dos cidadãos, como subjetiva. No caso brasileiro, ao contrário, por expressa disposição constitucional (art. 37, $\S 6^{\circ}, \mathrm{CF}$ ), a regra é da responsabilidade objetiva do Estado. Assim, as pessoas jurídicas de direito público e as de direito privado prestadoras de serviços públicos responderão, independente de culpa, pelos danos que seus agentes, nessa qualidade, causarem a terceiros, assegurado o direito de regresso contra o responsável nos casos de dolo ou culpa. Logo, seria necessário desconstitucionalizar dois direitos fundamentais expressos para se adotar a "lógica" de Herring $v$. United States.

Diante da relevância conferida à doutrina americana, salta aos olhos o uso deslocado do contexto dos argumentos sobre a relativização da prova ilícita. Esse uso descontextualizado atinge a validade dos argumentos de ordem pragmática apenas referidos, mas principalmente a validade dos argumentos formais que sustentaram a posição conservadora nos EUA.

Entretanto, tais ponderações ocultam outro problema grave que pode ser percebido pela comparação. A "desconstitucionalização" da regra da exclusão encontra no Brasil um cenário no qual a construção dos direitos fundamentais dos cidadãos exsurge como algo pouco consolidado no sistema jurídico constitucional. Uma análise diacrônica colocaria destaque a aplicação da regra da exclusão no sistema americano nos seguintes termos: sempre esteve presente no pano de fundo das discussões a respeito da exclusão das provas ilícitas que o Poder Judiciário americano tinha o dever de controlar o exercício da força exercido, de modo que era necessário que a polícia encontrasse limites rígidos a sua atuação em quanto braço ostensivo do Estado. No Brasil, o resultado da prática jurídica de outro país foi introduzido na Constituição como direito fundamental, porém, não há reformas institucionais ou legislativas significativas de controle da produção ilícita de provas e o Judiciário pouco tem se preocupado com padrões institucionais de controle da violência policial. ${ }^{98}$

Por sua vez, numa perspectiva sincrônica, convém observar rapidamente os casos julgados pela Suprema Corte Americana para que se possa ter em mente decisões em situação semelhante de nossos tribunais. Veja-se: a) Em Weeks v. United States (1914), quando a Suprema Corte reconheceu a regra da exclusão, um cidadão teve a casa invadida pela polícia, sem mandado judicial, e lá foram apreendidas evidências que o ligavam a práticas criminosas e provocaram sua condenação; b) Em Wolf v. Colorado (1949) e Mapp v. Ohio (1961), quando se debateu o reconhecimento como regra constitucional obrigatória aos estados, havia, no primeiro caso um cidadão que fora condenado por conspiração para realizar abortos criminosos, e, no segundo, Mapp teve sua casa invadida por policiais sem mandato, por acreditarem que ali estava abrigado um suspeito de bombardeiro; c) Em Calandra v. United States (1974), a decisão que provoca sua desconstitucionalização da prova ilícita, havia um cidadão que fora questionado em procedimento de júri acerca de seus vínculos com a atividade de agiotagem (loan sharking activities), a partir de evidências obtidas durante uma busca ilícita em seu escritório; d) Por fim, em Hudson v. United States (2006) e Herring v. United States (2009), precedentes que situam de forma preocupante o atual contexto de aplicação da regra, havia, no primeiro caso, um cidadão em cuja residência os policiais entraram, embora com mandado judicial, sem dar tempo hábil para que o morador abrisse

\footnotetext{
${ }^{97}$ Duarte, Evandro C. Piza; Murari, M. ; Lacerda, M. ; Deus Garcia, Rafael de. . Quem é o suspeito do crime de tráfico de droga? Anotações sobre a dinâmica dos preconceitos raciais e sociais na definição das condutas de usuário e traficantes pelos Policiais Militares nas Cidades de Brasília, Curitiba e Salvador.. In: Isabel Seixas de Figueiredo; Gustavo Camilo Baptista e Cristiane do Socorro Loureiro Lima. (Org.). Pensando a Seguranca Pública e Direitos Humanos: Temas Transversais. 1ed.Brasília: Ministério da Justiça (SENASP), 2014, v. 5, p. 81-120.

${ }^{98}$ Lemgruber, Julita; Musumeci, Leonarda; Cano, Ignácio (orgs.). Quem vigia os vigias? Um estudo sobre controle externo da polícia no Brasil, Rio de Janeiro/São Paulo, Record, 2003.
} 
a porta, e, no segundo, a polícia encontrou evidências da prática de crime, muito embora não possuísse mandado de busca e apreensão válido.

No caso brasileiro, a doutrina e dispositivos infraconstitucionais anteriores à Constituição de 1988, segundo os quais cabe flagrante delito em crime permanente, têm servido para justificar uma silenciosa relativização de um dos poucos dispositivos explícitos do art. $5^{\circ}$ da Constituição sobre a inviolabilidade de um direito fundamental (o direito à inviolabilidade do domicílio), estendendo a noção de flagrante para casos nos quais não há uma situação de risco imediato de lesão a direitos, e em que a solicitação prévia de mandado judicial e o respectivo controle jurisdicional seria possível, sem qualquer prejuízo para a investigação. O Supremo Tribunal Federal, no RE 603.616, corroborou às práticas policiais arbitrárias vinculadas à Guerra às Drogas, propondo uma doutrina inconstitucional de validação a posteriori dos atos processuais. ${ }^{99}$

A observação dos casos concretos traz à tona um elemento silencioso e reincidente, a conivência das instituições jurídicas, especialmente da Magistratura, com padrões reduzidos de garantias processuais relativos às práticas de policiamento/investigação criminal, cerne das questões relacionadas à prova ilícita.

No Brasil, portanto, há uma interpretação constitucional leniente em relação ao alcance do poder policial para invadir a esfera privada, presente em dispositivos legais, práticas judiciais e ausência de mecanismos de fiscalização/transparência, os quais potencializam a existência de "penas sem processo" e "processos penais como punição". ${ }^{100}$ Nos EUA, o debate se estabelece num cenário em que a regra é a necessidade de autorização judicial prévia para a invasão da privacidade. Os discursos sobre a relativização da prova ilícita, sob esse prisma, não trazem apenas o risco da desconstitucionalização, sempre autoritária, de direitos, justificada por meio do trânsito de ideias deslocadas de seu contexto, mas, ao revés, a desconstrução de lutas sociais e jurídicas pela construção de direitos fundamentais dos acusados em outros temas que aqui são ainda mais frágeis do que no contexto estadunidense. ${ }^{101}$

Por fim, a relativização da prova ilícita, no caso brasileiro, violenta o contexto de origem. De fato, os argumentos conservadores que a sustentam no judiciário estadunidense insistem no fato de que a exclusão da prova ilícita não é norma expressa da Constituição, ou seja, que se trata de uma criação judicial. Aqui a proposta pretende violentar norma constitucional expressa, a pretexto de modernizar a legislação infraconstitucional. Dificilmente, nem mesmo o mais conservador dos juízes americanos, aceitaria ou proporia abertamente tamanha traição de contexto ao sistema constitucional. A distância é tamanha que, conforme mostram os indícios, estamos aqui diante de um caso particular de Traduttori Traditori Constitucionais.

\footnotetext{
99 Sobre a construção da política de drogas, veja-se: Malaguti, Vera Batista. Difíceis ganhos fáceis: drogas e juventude pobre no Rio de Janeiro. Rio de Janeiro: Instituto Carioca de Criminologia/Freitas Bastos Editora, 1998. Sobre o comportamento do judiciário em relação à ação policial, veja: Wanderley, Gisela Aguiar. A busca pessoal no direito brasileiro: medida processual probatória ou medida de polícia preventiva? Revista Brasileira de Direito Processual Penal, Porto Alegre, v. 3, n. 3, p. 1117-1154, set. 2017. https://doi. org/10.22197/rbdpp.v3i3.96. Duarte, Evandro C. Piza; Muraro, M. ; Lacerda, M. ; Deus Garcia, Rafael de. . Quem é o suspeito do crime de tráfico de droga? Anotações sobre a dinâmica dos preconceitos raciais e sociais na definição das condutas de usuário e traficantes pelos Policiais Militares nas Cidades de Brasília, Curitiba e Salvador.. In: Isabel Seixas de Figueiredo; Gustavo Camilo Baptista e Cristiane do Socorro Loureiro Lima. (Org.). Pensando a Seguranca Pública e Direitos Humanos: Temas Transversais. 1ed.Brasília: Ministério da Justiça (SENASP), 2014, v. 5, p. 81-120.

${ }^{100}$ Zaffaroni, Eugenio Raúl. Em busca das penas perdidas: a perda de legitimidade do sistema penal. Rio de Janeiro: Revan, 1991.

${ }_{101}$ Mantem-se aqui e nos EUA, por estratégias diversas padrões coloniais e racializados de controle sócio-penal. Veja-se: Duarte, Evandro Piza; Garcia, Rafael de Deus e Queiroz, Marcos V. Lustosa. “A Rebelião da Prisão de Attica (Nova Iorque, 1971): Opressão Racial, Encarceramento em Massa e os Deslocamentos da Retórica da Igualdade". In: Revista de Estudos Criminais, Ano XV, ${ }^{\circ} \quad 61, \quad 2016$. Duarte, Evandro Piza; Queiroz, Marcos V. Lustosa; Costa, Pedro H. Argolo. "A Hipótese Colonial, um diálogo com Michel Foucault: a Modernidade e o Atlântico Negro no centro do debate sobre Racismo e Sistema Penal". In: "Universitas Jus", v. 27, p. 01-31, 2016.
} 


\section{BIBLIOGRAFIA}

ANDRADE, Vera Regina Pereira de. Minimalismos, abolicionismos e eficienticismo: a crise do sistema penal entre a deslegitimação e a expansão. Revista Sequência, no 52, p. 163-182, jul. 2006.

BADARÓ, Gustavo. As propostas de alteração do regime de provas ilícitas no processo penal. Boletim 277 do Instituto Brasileiro de Ciências Criminais, 2015.

BRADLEY, Craig. Is the exclusionary rule dead? The Journal of Criminal Law and Criminology, Vol. 102, No. 1, pp. 1-23. Chicago: Northwestern University School of Law, Winter 2010.

BRADLEY, Craig M. Red Herring or the death of the exclusionary rule? Trial Magazine, Indiana Legal Studies Research Paper, No. 129. Washigton: The American Association for Justice, 2009.

CARVALHO, Salo de. A política criminal de drogas no Brasil: estudo criminológico e dogmático da Lei 11.343/06. RJ, 2014, p. 55-85.

CLANCY, Thomas K. The fourth amendment's exclusionary rule as a right. Ohio State Journal of Criminal law, v. 10, p. 357-391, 2012.

COMMACK, Mark E. The rise and the fall of the exclusionary rule in United States. The American Journal of Comparative Law, v. 58, p. 631-658, 2010.

COOLEY, Thomas M. Princípios Gerais de Direito Constitucional nos Estados Unidos da América. Belo Horizonte: Universal, 2016.

DUARTE, Evandro Piza, GARCIA, Rafael de Deus e QUEIROZ, Marcos V. Lustosa. “A Rebelião da Prisão de Attica (Nova Iorque, 1971): Opressão Racial, Encarceramento em Massa e os Deslocamentos da Retórica da Igualdade”. In: Revista de Estudos Criminais, Ano $\mathrm{XV}, \mathrm{n}^{\mathrm{o}}$ 61, 2016.

.; QUEIROZ, Marcos V. Lustosa; COSTA, Pedro H. Argolo. "A Hipótese Colonial, um diálogo com Michel Foucault: a Modernidade e o Atlântico Negro no centro do debate sobre Racismo e Sistema Penal”. In: “Universitas Jus”, v. 27, p. 01-31, 2016.

.; MURARO, M. ; LACERDA, M. ; DEUS GARCIA, Rafael de. . Quem é o suspeito do crime de tráfico de droga? Anotações sobre a dinâmica dos preconceitos raciais e sociais na definição das condutas de usuário e traficantes pelos Policiais Militares nas Cidades de Brasília, Curitiba e Salvador.. In: Isabel Seixas de Figueiredo; Gustavo Camilo Baptista e Cristiane do Socorro Loureiro Lima. (Org.). Pensando a Seguranca Pública e Direitos Humanos: Temas Transversais. 1ed.Brasília: Ministério da Justiça (SENASP), 2014, v. 5, p. 81-120.

ESTADOS UNIDOS. Constituição. Emenda Constitucional n. 4, 1791.

. Suprema Corte. Brown v. Mississippi, 1936.

. Suprema Corte. Calandra v. United States, 1974.

Revista de Direito Brasileira | Florianópolis, SC | v. 27 | n. 10 | p.216-240 | Set./Dez. 2020 
. Suprema Corte. Herring v. United States, 2009.

. Suprema Corte. Hudson v. United States, 2006.

. Suprema Corte. Hurtado v. California, 1884.

. Suprema Corte. Leon v. United States, 1984.

. Suprema Corte. Mapp v. Ohio, 1961.

. Suprema Corte. Massiah v. United States, 1964.

. Suprema Corte. Miranda v. Arizona, 1966.

. Suprema Corte. Palko v. Connecticut, 1937.

. Suprema Corte. Twining v. New Jersey, 1908.

. Suprema Corte. Weeks v. United States, 1914.

Suprema Corte. Wolf v. Colorado, 1949.

ESTAMPRES, Manuel Miranda. La prueba ilícita: la regla de exclusion probatoria y sus excpeciones. Revista Catalana de Seguretat, p. 131-151, 2010.

1999.

. El concepto de prueba ilícita y su tratamento en el proceso penal. Barcelona: JMB,

FERRAJOLI, Luigi. Direito e razão: teoria do garantismo penal. São Paulo: RT, 2002.

GARCIA, Rafael de Deus. O Uso da Tecnologia e a Atualização do Modelo Inquisitorial: Gestão da Prova e Violação de Direitos Fundamentais na Investigação Policial na Política de Drogas. Belo Horizonte: Lumen Juris, 2017.

GITTINS, Jeffry. Excluding the Exclusionary Rule: Extending the Rationale of Hudson v. Michigan to Evidence Seized During Unauthorized Nighttime Searches. Brigham Young University Law Review, Vol. 2007, N. 2, p. 451-481, 2007.

GOMES FILHO, Antônio Magalhães. Direito à prova no processo penal. São Paulo: Revista dos Tribunais, 1997.

HENNING, Anna C. Rule in fourth amendment cases. Congressional Research Service. p. 73$84,2009$.

LEMGRUBER, Julita; MUSUMECI Leonarda; CANO, Ignácio (orgs.). Quem vigia os vigias? Um estudo sobre controle externo da polícia no Brasil, Rio de Janeiro/São Paulo, Record, 2003.

KANT DE LIMA, Roberto. Direitos civis e Direitos Humanos: uma tradição jurídica prérepublicana? São Paulo em perspectiva, São Paulo, v. 8, p.49-59, jan./mar. 2004. 
LAFAVE, Wayne R. The Smell of Herring: A Critique of the Supreme Court's Latest Assault on the Exclusionary Rule, 99 J. Crim. L. \& Criminology 757, 77778 (2009).

LEMGRUBER, Julita; MUSUMECI, Leonarda; CANO, Ignácio (orgs.). Quem vigia os vigias? Um estudo sobre controle externo da polícia no Brasil, Rio de Janeiro/São Paulo, Record, 2003

LOPES JR., Aury. Introdução crítica ao processo penal: fundamentos da instrumentalidade garantista. 3. ed. Rio de Janeiro: Lúmen Juris, 2005.

MALAGUTI, Vera Batista. Difíceis ganhos fáceis: drogas e juventude pobre no Rio de Janeiro. Rio de Janeiro: Instituto Carioca de Criminologia/Freitas Bastos Editora, 1998.

MCDONALD, Marc. W. The good faith exception to the exclusionary rule: United States v. Leon and Massachusetts v. Sheppard. Boston College Law Review, v. 27, n. 609, p. 609-640, 1986.

NEUBORNE, Burt. Fundamentals of American Law. New York: New York University School of Law, pp. 86-93, 1996.

OLMO, Rosa de. América Latina y su criminologia. México: Siglo Veintiuno, 1984

PELELLA, Eduardo; CALABRICH, Bruno e FISCHER, Douglas. Garantismo Penal Integral $2^{\circ}$ edição: revista, ampliada e atualizada. 2 ed. Salvador/BA: Juspodivm, 2013. 520p.

RE, Richard M. The due process exclusionary rule. Harvard Law Review, v. 127, n. 7, p. 18871966, 2014.

SKLANSKY, David Alan. Is the exclusionary rule obsolete? Ohio State Journal of Criminal Law, v. 5, n. 567, p. 568, 2008

SILVA, José Afonso. Aplicabilidade das Normas Constitucionais. São Paulo: Editora Malheiros, 2012.

SOZZO, Máximo. Tradutore traditore. Traduc-ción, importación cultural e historia del presente de la criminología en América Latina. In: . (ed.): Reconstruyendo las criminologías críticas, Ad-Hoc, Buenos Aires, 2006.

TAKAYANAGI, Fabiano Yuji. Críticas às exceções legais às provas ilícitas por derivação no processo penal brasileiro e análise de jurisprudência após a reforma da lei 11.690/08. 2014. Dissertação (Mestrado em Direito Processual) - Faculdade de Direito, Universidade de São Paulo, São Paulo, 2014.

TAVORA, N. ; ALENCAR, R. A. R. C. Curso de direito processual penal. 12. ed. Salvador/BA: Juspodivm, 2017. v. 1. 1840p. 
WANDERLEY, Gisela Aguiar. Liberdade e Suspeição no Estado de Direito: o poder policial de abordar e revistar e o controle judicial de validade da busca pessoal. Dissertação de mestrado no curso de Pós-Graduação em Direito da Universidade de Brasília, 2017

ZAFFARONI, Eugenio Raúl. Em busca das penas perdidas: a perda de legitimidade do sistema penal. Rio de Janeiro: Revan, 1991. 